\title{
OCCLUSAL SURFACE ACHIEVED USING THE STAMP TECHNIQUE
}

\author{
MONA IONAŞ ${ }^{1}$, ADELA DĂNCIL $\breve{A}^{2}$ \\ 1,2 "Lucian Blaga” University of Sibiu \\ Keywords: $\quad$ occlusal Abstract: Dental occlusion can be restored through preparation, modelling, occlusal adjustment and \\ filling, stamp technique finishing or by reproducing the final future tooth surface. The micro-brush stamp technique is a new \\ technique used in direct restorations. The purpose of this paper is to present a fast way of restoring \\ the occlusal surface of a tooth when a previous correct functional impression of the surface exists. We \\ will approach, step by step, the occlusal dental tissue reconstruction using a dental flowable \\ composite and a microbrush to get a stamp of the occlusal surface in order to achieve precise occlusal \\ topography
}

\section{INTRODUCTION}

Practitioners discovered that the uneven relief of the occlusal surface is a possible cause for the occurrence of occlusal caries.

Direct restorations are used daily in order to restore the functions of the dental system. The quality and working technique are being constantly improved. Aesthetics is very important in anterior teeth, both the colour and the restoration being of great significance, meanwhile for the posterior dental those steps are not so significant. When an imbalance between demineralization and remineralization occurs, various lesions appear on the enamel. Over time, the surface becomes fragile and the affected enamel becomes a perfect environment for the growth and development of bacteria. Due to the occlusal relief with ditches and dimples difficult to clean, the enamel on the occlusal surface is suitable for the multiplication of bacteria. The direction in which the dentinal tubules are oriented, determines how a lesion can evolve. In enamel, tooth decay evolves in the form of a triangle with the base down and the tip up, that is why caries often seem small on the surface but in fact, the deeper you go, the deeper they become.(1)

Composite fillings have gained more ground than amalgam fillings, although a doctor's dexterity and experience is required in making an aesthetic composite filling. The technique of making a composite filling material is much more demanding than the amalgam filling at a similar cavity. When we work with composite materials, special attention must be paid to the isolation stages, insertion and polymerization of composite materials in the cavity and also the finishing and polishing require more time than the amalgam filling. If the occlusion is not well balanced, there may occur changes in the stability of the entire stomatognathic system and orofacial integrity, so occlusion is a key element for the psychosocial wellbeing. $(2,3,4)$

Nowadays, dental composites can be applied in layers up to $4 \mathrm{~mm}$ thick in a single layer (bulk fill materials), thus decreasing the curing time comparing to the standard $2 \mathrm{~mm}$ thick layer. $(5,6)$
The placement of composite requires skilful performance of the dentist, occlusal adjustment and finishing procedure. Occlusal adjustment procedure is a difficult part in direct restorations. Often a direct composite restoration does not fully reproduce the morphology and occlusion as an indirect technique would reproduce. To reduce the working time allocated to occlusal adjustment and to improve the correctness of surface morphology, two techniques are available using a silicon key. One is done using a duplicate of a wax-up model created by a dental technician, the other one is done using a duplicate of an old filling considered correct from the morphofunctional point of view. $(7,8,9,10)$ The idea of using a dental flowable composite in order to duplicate a dental surface was recently introduced.(11)

During occlusal adaptation of the fillings, it must be taken into account that a possible modification of the occlusion is considered iatrogenic that could modify the stability of the entire stomatognathic system.(12) Adaptation of the temporomandibular joint, neuro muscles and its supporting structures is favoured by a functional occlusion while maintaining a stable centric occlusion relationship and maximum intercuspidation without signs of tooth wear and without symptoms of mandibular dysfunction. $(13,14)$ Psychosocial well-being is also given by a functional occlusion, and orofacial integrity is a key element in maintaining this balance. $(15)$

\section{AIM}

The aim of this paper is to present a fast way of restoring the occlusal surface of a tooth, using a dental flowable composite when a previous correct functional impression of the surface exists.

\section{MATERIALS AND METHODS}

We used bulk-fill composite. It was chosen due to the one-step placement of larger increments, where additional layers are not needed. The instrument used is a Comporoller (Kerr) which is enough when applying the increment.

${ }^{1}$ Corresponding author: Mona Ionaş, Str. Lucian Blaga, Nr. 2A, Sibiu, România, E-mail: mona.ionaş@ulbsibiu.ro, Phone: +40726 229642 Article received on 01.04.2020 and accepted for publication on 10.07.2020 
CLINICAL ASPECTS

The working technique requires the following steps:

- Rubber dam isolation placement

- Teflon Tape placement on the occlusal surfaces of the teeth (CROMWELL tape $12 \mathrm{~mm} \times 12 \mathrm{M}$ );

- Flowable composite in this case green liquid rubber dam (Rubber Dam Liquid, Cerkamed) application over it in order to cover the occlusal surface;

- Introducing a micro-brush in the green liquid rubber dam with gentle digital pressure so that the tip does not reach the occlusal surface and light cure polymerization (figure no.1);

- Appropriate preparation for the oral cavity, etching with phosphoric acid 37\% (figure no. 2), Single Bond II (3MEspe) placement,(figure no. 3) 5 seconds Elipar Free Light 2 (3M-Espe) light cure, Filtek Bulk Fill (3M- Espe) material insertion, leaving $1 \mathrm{~mm}$ space under the occlusal surface, followed by 10 seconds Elipar FreeLight 2 (3MEspe) light cure;

- The last layer of solid composite, Filtek Bulk Fill (3MEspe), (figure no. 4), Teflon Tape placement and compressing with occlusal stamp, (figure no. 5), removing it and any composite material excess, followed by 10 seconds Elipar FreeLight 2 (3M-Espe) composite material light curing;

Figure no. 1. The impression is made out of green liquid rubber dam and it is applied all over the occlusal surface after the microbrush is pressed on the green liquid rubber dam with gentle digital pressure so that the tip does not reach the occlusal surface

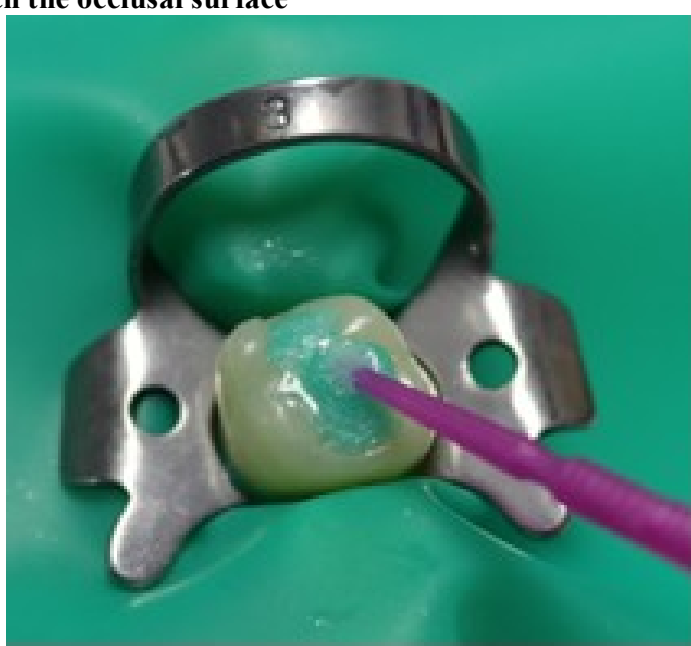

Figure no. 2. Etching with $37 \%$ ortho phosphoric acid

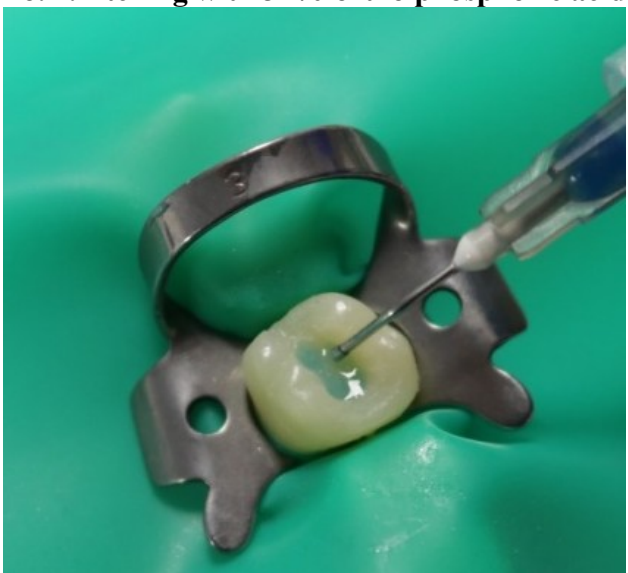

Figure no. 3. Applying the bonding agent

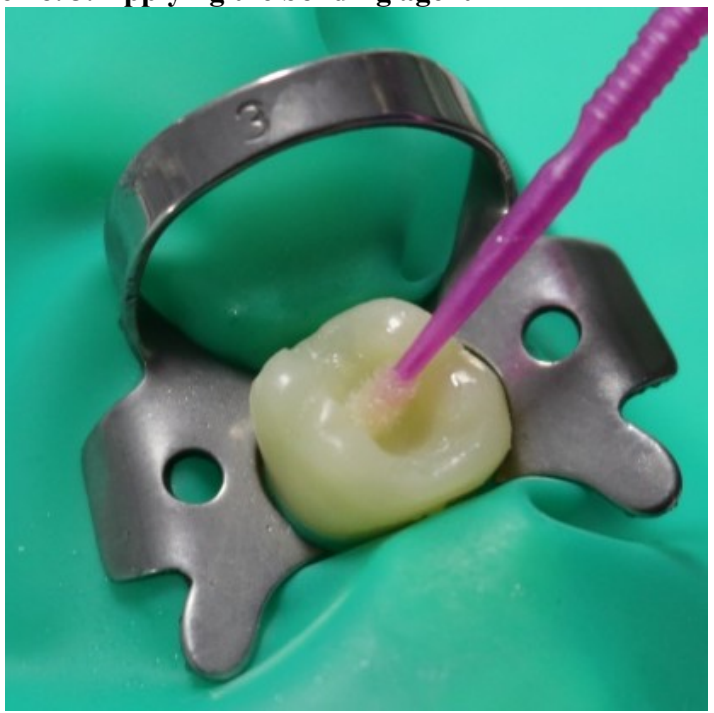

Figure no. 4. Filtek Bulk Fill (3M-Espe) is applied

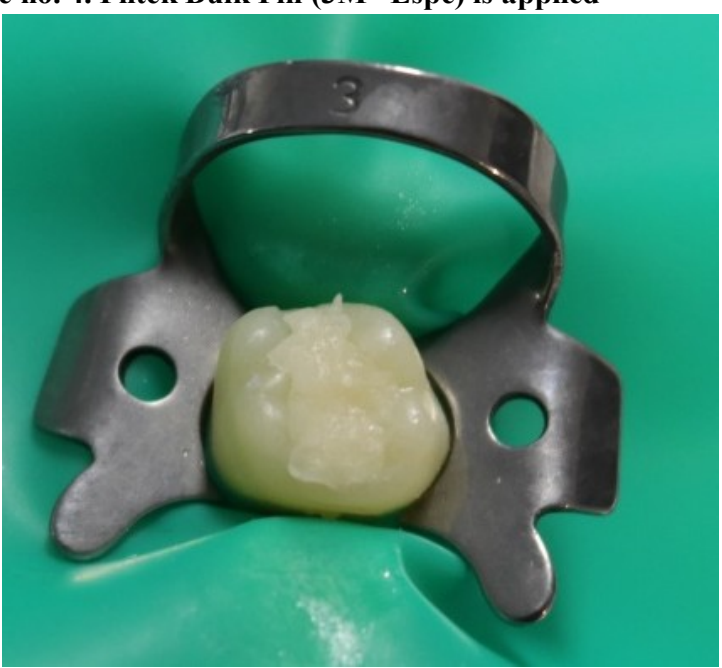

Figure no. 5 Microbrush stamp is pressed over the teflon band

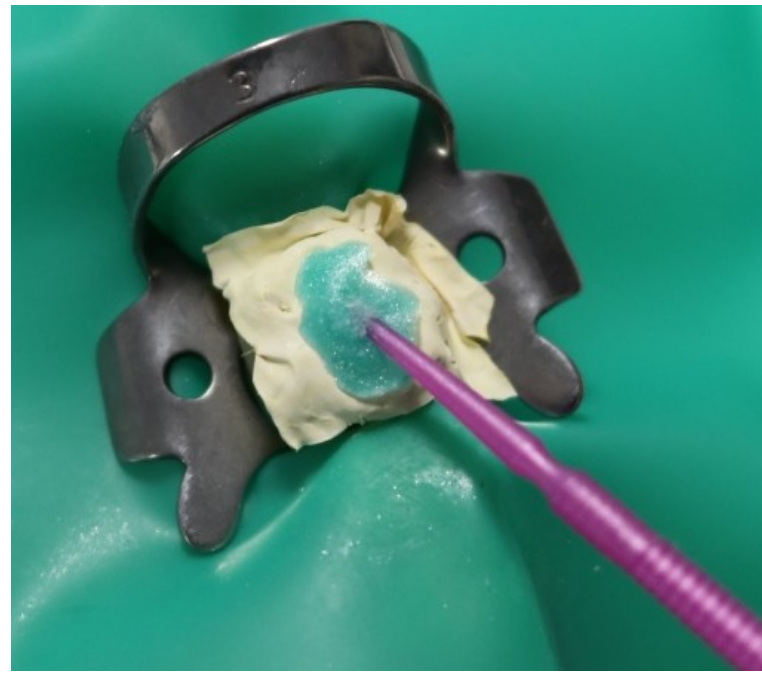

- Checking the occlusal adaptation and the the finishing. To remove the debris a pumice was used. Under low speed a rubber cup in a contra angle micromotor handpeice was used for pumice prophylaxis.(figure no. 6). 


\section{CLINICAL ASPECTS}

Figure no. 6. Final restoration aspect of the composite filling

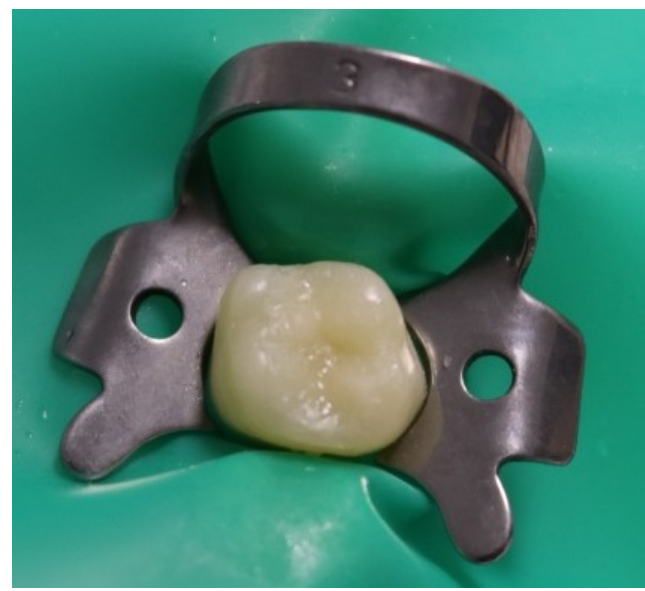

RESULTS AND DISCUSSIONS

A rapid integration in the dental system and shorter occlusal adjusting time are obtained.

The stamp technique is a fast procedure with decreased chair side time in recreating occlusal anatomy and also in polishing and finishing. No need for special instruments is required because it replicates the original occlusal anatomy since it is a copy of the occlusion, and not made by hand, the material consumption is also minimum.

We have to mention that the technique has a few minuses. Among them is the use of materials, a microbrush, a flowable composite material or green liquid rubber dam that are expensive. Another downside would be a failure in restoration when the stamp is not positioned correctly or comes off the microbrush when handling.

A lot of considerable time is spent to master and practice this technique. But in time, with practice, this can be easily overcome. To achieve the objective of obtaining an accurate cusp-fossa relationship, it is imperative to mention that the correct and precise placement of the occlusal stamp is a prerequisite. The main objective of the technique is cancelled without a correct and precise placement, otherwise distortion results.

With this technique, the degree of porosities that are present in the final restoration is reduced. Decreasing formation of microbubbles is due to the fact that the stamp matrix exerts pressure on the composite. The interference of oxygen with polymerization of the final layer of composite is minimum. That is why it is indicated for this technique to select the cases preoperatively, with preserved anatomy of pit and fissure caries.(16)

In order to easily reconstruct the missing external tooth structure, a matrix is used for inserting a composite material, but in order to restore occlusal surfaces a free hand sculpt of this anatomical surface is performed risking an inadequate remake.(17,18,19) This technique can be used in cases where the caries is evident during the clinical examination or routine radiographic examination of teeth with intact marginal ridges and ideal occlusal anatomy or when dealing with an incorrect from the colour point of view but correctly occlusal morphofunctional sculpted previous filling.(11,20) To use this technique one will need the materials normally found in a dental office. We include here a dental composite material (classic type, applied in layers of $2 \mathrm{~mm}$ or bulk-fill type with layers of up to $4 \mathrm{~mm}$ ), filling instruments, a flow dental composite, a microbrush and a dental adhesive (use of phosphoric acid $37 \%$ depends on adhesion technique).(21) The only added material to the dental composite filling technique in order to restore the occlusal surface is a teflon band which is frequently used to protect teeth/implants in adhesive procedures.

The surface smoothness is improved when duplication of the occlusal surface takes place in advance.(22) Occlusal problems are due to changes in the occlusal morphology. Any inadequate occlusal adjusting can cause primary occlusal trauma, due to interference or premature contact. The advantage of this technique is that it maintains the initial anatomy of the tooth.(23) In fact, the length of time for occlusal adjustment is reduced to minimum, thus maintaining the marginal continuity and the surface of the filling, preventing microfractures from forming as a side effect of using the dental drill.(24)

\section{CONCLUSIONS}

Using the micro-brush stamp technique to restore the occlusal surface we obtain fast, simple and predictable integration of the new restoration in the teeth occlusal function.

When the operator is skilled, this stamping technique for direct composite restorations is a favourable and convenient procedure. This technique can be adapted even to unconventional cavities because the accuracy of topography replication is much higher than the conventional method.

\section{REFERENCES}

1 Stanley N, Major A. Wheeler's Dental Anatomy, Physiology and Occlusion, Saunders; 2009.

2 Murrashkin A. Direct posterior composite restorations using stamp technique-conventional and modified: A case series. IJDR. 2017;2:3-7.

3 Christensen GJ, Simon JF, Strassler HE. The Amalgam Controversy: Where Do We Go From Here? Compendium. 2011;32(6).

4 Diley DC, Vann WF Jr., Oldenburg TR, Crisp RM. Time required for placement of composite versus amalgam restorations. ASDCJ Dent Child. 1990;57:177-83.

5 Christensen GJ. Longevity of posterior tooth dental restorations. Journal of the American Dental Association. 2005;136(2):201-203.

6 Ionaş M. Particularities of treatment with bulk fill flow composites. Acta Medica Transilvanica. 2017;1(22):75-77.

7 Varsha RK. Microbrush Stamp Technique - Case report, General Practice Feature. Dentaltown. 2015;98-9.

8 Perrin P, Zimmerli B, Jacky D, Lussi A, Helbling C, Ramseyer S. The stamp technique for direct composite restoration. Schweiz Monatsschr Zahnmed. 2013;123(2):111-29.

9 Ramseyer T, Helbling C, Lussi A. Vertical Bite Reconstructions of Erosively Worn Dentitions and the Stamp Technique - A Case Series with a Mean Observation Time of 40 Months. The Journal of Adhesive, Dentistry. 2015;17(3):68-9

10 Părău D, Bizgan OC, Sabău M, Ionaş M. Stratification technique of a nanocomposite using the silicon guide. International Journal of Medical Dentistry. 2015;2(5):138142 .

11 Alshehadat SA, Halim MS, Carmen K, Fung CS. The stamp technique for direct Class II composite restorations: A case series. J Conserv Dent. 2016;19:490-3.

12 Dawson EP. Evaluation, Diagnosis and treatment of Occlusal problems, 2nd Ed., C.V. Mosby Co.(Toronto); 1989.

13 Gross MD, Mathews JD. Occlusion in Restorative Dentistry, Technique and Theory, I st Ed. Churchill Livingston (NY): Longman Group limited; 1982.

14 Roberson TM, Heymann IV, Swift HV, Edward J.VI, Sturdevant, Clifford M. Sturdevant's Art and Science of Operative Dentistry, 5 th Ed. Mosby 
publications(PA):Elsevier limited; 2006.

15 Klienburg I, Jagger R. Occlusion and Clinical Practice : An Evidence Based Approach 1 st Ed. Wright publications (UK):Elsevier limited; 2004.

16 Moraru I, Bugală A, Gheorghe A, Popescu D, Râcă AM. Why using the stamp technique in classs I cavities is a first choice filling technique. Romanian Journal of Medical and Dental Education. 2019;8(1):54-59.

17 Geena M, Ambily J. Microbrush stamp technique to achieve occlusal topography for composite resin restorations - A Technical Report. Journal of Scientific Dentistry. 2016;6,(2):76-82.

18 Simon T. Ramseyer, Christoph Helbling, Adrian Lussi. Vertical Bite Reconstructions of Erosively Worn Dentitions and the "Stamp Technique" - A Case Series with a Mean Observation Time of 40 Months. The Journal of Adhesive Dentistry. 2015;17(3):68-99.

19 Martos J, Silveira LM, Ferrer-Luque CM, González-López $\mathrm{S}$. Restoration of posterior teeth using occlusal matrix technique. Indian J Dent Res. 2010;21(4):596-599.

20 Alshehadat SA, Halim MS, Carmen, Fung CS. The stamp technique for direct class II composite restorations: A case series. J Conserv Dent. 2016;19:490-493.

21 Savin C, Petcu A, Gavrila L, et al. Dental materials for coronary obturation utilized in pedodontics. Int. J. of Medical Dentistry. 2016;20(3):171-176.

22 Hamilton JC, Krestik KE, Dennison JB. Evaluation of custom occlusal matrix technique for posterior light-cured composites. Oper Dent. 1998;23:303-307.

23 Carranza S. Clinical Periodontologiy 9th ed, W..B., Saunders; 2002.

24 Ritter AV. Direct resin-based composites: current recommendation for optimal clinical results. Compendium. 2005;26(7):481-492. 